\title{
Defining elements of sustainable work systems - a system-oriented approach
}

\author{
Klaus Fischer ${ }^{\mathrm{a}^{*}}$ and Klaus J. Zink ${ }^{\mathrm{b}}$ \\ ${ }^{a, b}$ Research Institute for Technology and Work, University of Kaiserslautern, Kurt-Schumacher-Str. 74a, 67663 \\ Kaiserslautern, Germany
}

\begin{abstract}
Based on a system-theoretic discussion of sustainability, this paper aims to develop a conceptual model of a sustainable work system which is consistent with the definition of ergonomics by the IEA in 2000 (but also with earlier definitions) as well as with the triple bottom line understanding of sustainable development comprising the management of human, social, ecological and economic capital in a balanced manner.
\end{abstract}

Keywords: Sustainable development, sustainable work system, system theory, keyword four, keyword five

\section{Introduction}

The global vision of sustainable development as defined by the WCED in 1987 [1] delineates a rather superordinated concept for the future development of our earth system. Interpreting this concept in a system-theoretic manner can help to transfer sustainability principles and criteria to relevant sub-systems as e.g. economics, organizations and also work systems. Thus, taking the perspective of systems theory supports to understand what "sustainability" means for the whole system of our global human population as well as for its sub-systems. Such a perspective also allows to show which requirements result from "overall sustainability" in regard to the sustainability of sub-systems.

Coming along with the increasing debate on sustainable development and corporate social responsibility, several authors refer to "sustainable work systems" in the last years (cp. e.g. the edited volumes on "sustainable work systems" from Docherty et al. in 2002 and 2009 [2; 3]). Thereby, the debate often focuses on work intensity $[4$, p. 51] which is of course a central aspect of work systems sustainability but does not per se strive towards a full triple bottom line understanding.

Based on a system-theoretic discussion of sustainability as outlined above, this paper aims to develop a conceptual model of a "sustainable work system" which is consistent with the definition of ergonomics by the IEA in 2000 [5] (but also with earlier definitions $[21 ; 22])$ as well as with the triple bottom line understanding of sustainable development - comprising the management of human, social, ecological and economic capital in a balanced manner.

The model thereby aims to

- visualize the relations between different system elements, inputs and outputs as well as influencing variables on work systems sustainability,

- give some kind of conceptual framework for linking different complementary research perspectives and approaches which are (besides ergonomics) relevant for the design of sustainable work systems

- show how the ergonomics' object of research is linked with those of other scientific disciplines, thus focusing on the embeddedness of (sustainable) work systems in their societal, economic and environmental surroundings.

\section{Characteristics of systemic modeling}

The terms "system" and "systemic" found their way into our everyday speech for some time now and are also - however, with varying meanings - widely used in the language of science.

\footnotetext{
*E-mail: klaus.fischer@ita-kl.de
} 
But when talking about "work systems" or even more about "sustainable work systems" a closer look to the true acceptation of what we call a system seems to be adequate. Thus, this paragraph aims to introduce some general principles of systemstheoretical modeling and will also present its outstanding qualification for analyzing sustainable work systems.

It is highly relevant how we model a system and which "section" of reality our model comprises then. Thereby, the scope of a system definition depends on the modeling process itself, as "A system is not something given in nature, but something defined by intelligence“ [6, p. 242]. Systems can thus be seen as some kind of "a list of variables"[7, p. 40] chosen by the respective "observer" or modeling person/discipline.

But this list of variables cannot be selected arbitrarily. The principles of systems thinking and modeling (see below) rather require to "select, from an infinite number of relations between things, a set which, because of coherence and pattern and purpose, permits an interpretation of what might otherwise be a meaningless cavalcade of arbitrary events" [6, p. 243].

Consequently, by defining systems it is of major importance to preserve coherencies and interrelations as well as to accept that "the whole is greater than the sum of its parts" as Aristotle already stated.

The following general principles of systems theory and modeling can be identified [8, p. 52-57].

Systemic thinking is thinking in open systems:

Systems theory differs between closed and open systems. As closed systems by definition do not have any exchange of matter, energy or information with their environment, they only play a marginal role in theory and practice, as e.g. in thermodynamic research. Evidently, most systems are open and depend on the interrelations and exchange with their surroundings to survive. This is also true for work systems (see Figure 3). Thereby, the systems approach also requires to model them accordingly, recognizing these interrelations and interdependencies with surrounding environments as well as sub-systems and not treating them in an isolated way.

Systems thinking means to consider interrelations given in reality:

Cause-and-effect relationships are often modeled as linear processes, meaning that one cause may have one or a couple of clearly defined numbers of effects. This approach can still be found as a "normal case" throughout all disciplines: "The dominant research paradigm is still reductionist in nature, stressing analysis, static views, fragmentation, and linear thinking" [9, p. 50-51].

Thus, it is necessary to develop from linear thinking in isolated problems to a more coherent and holistic thinking and modeling in order to find a solution for the complexity of real problems.

Systemic thinking means changing levels of abstraction:

Systemic modeling aims to preserve coherency between super- and sub-systems and thus assumes that every system is part of a superordinated one and also further contains itself in sub-systems and elements. Thereby, analytical and synthetical thinking are combined, meaning that detailed knowledge about one system can be joined with "black box-knowledge" of others.

Thus, according to systems theory work systems are not limited to work place level but can also be modeled on corporate/organizational level or even on the level of economic sub-systems (as industries). Of course, for ergonomics and human factors, the traditional work system level is the most adequate. But the links to superordinated systems have to be considered, too.

\section{Sustainable Development from a system- theoretic point of view}

The current paradigm of sustainable development bases on the idea of managing environmental, social and economic capital stocks in a manner, that human needs can be satisfied in the present as well as in the future [1]. Thereby, satisfying the basic needs of all humans living on earth has priority and can be seen as a "minimum requirement" for sustainable development (intra- and inter-generation fairness).

"Sustainability" in a system theoretic view first of all means that a system is able to keep up a certain configuration on the long-term [10]. This configuration is also called "viable" in cybernetics (cybernetics can be very shortly characterized as the science about steering dynamic systems) and comes along with certain principles for the design of "viable systems" [6]. A general principle of the viable systems theory is, that each subsystem should on the one hand have a maximum of autonomy (regarding the handling of complexity by its own), while on the other hand its autonomy needs to be limited when the viability of the overall system is endangered $[11 ; 12]$. 
Applying viable systems theory to our overall social system called "human population" and its respective sub-systems finally gives a well-founded explanation for a "policy deployment" of sustainable development principles to sub-systems' level.

Assuming that the viability of our global social system depends on achieving sustainable development, we see that the autonomy of economic subsystems as organizations and work systems needs to be limited in those cases when overall system viability is affected, e.g. when human, social, economic or environmental capital is consumed and their reproduction disturbed.

In the next paragraph a short synopsis of different understandings and definitions of the terms "work system" as well as - more recently - "sustainable work system" is given. Thereby, these definitions will be contrasted with the above discussed principles of system-oriented modeling and the roughly delineated ideas of the viable systems theory.

\section{4. (Sustainable) Work Systems}

\subsection{The “common” linear work system model}

In general, a work system can be defined as "a system in which human participants and/or machines perform business processes using information, technologies, and other resources to produce products and/or services for internal or external customers." [13, p. 92].

Thereby, the basic work system model of ergonomics is quite reductionist.

It shows a linear process transforming a certain input of raw materials, intermediate goods or other commodities (generally spoken matter, energy and information) into a well-defined output of goods and services produced and residuals (matter', energy' and information'). Main elements of this system model are one (or more) working persons, interacting with different means for work, e.g. machines, tools in a work process (see Figure 1) [14; 15].

The external environments are modeled as sources of facilitating or hindering influences, as e.g. climate conditions or certain social, cultural and organizational impacts.

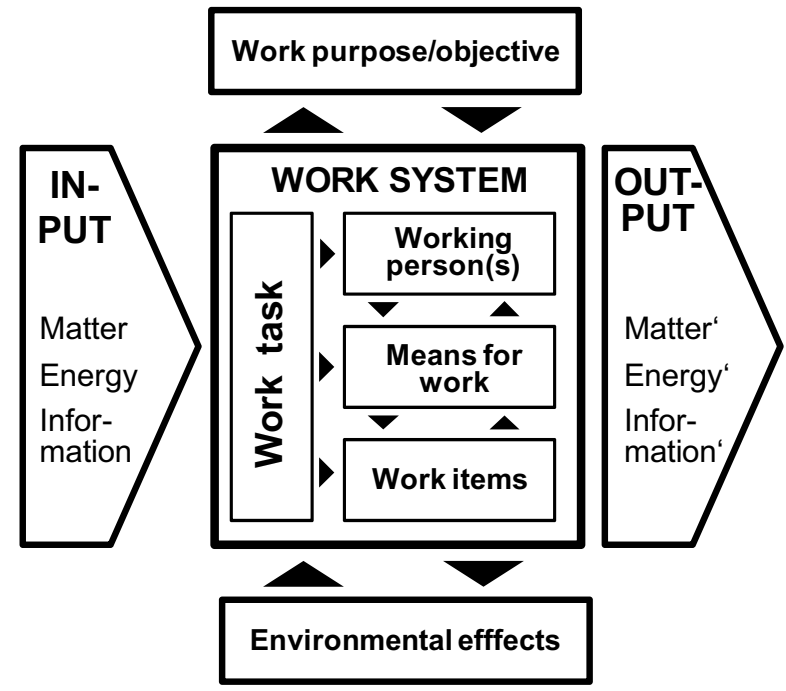

Figure 1: General work system model [cp. 14; 15]

Regarding the above presented principles of systemic modeling, this model is blinding out several fundamental coherencies.

As already mentioned, all work systems are open systems which interact with their surrounding societal, economic and ecologic environments in order to stay viable. Merely reducing these interrelations to the parameters "input/output" and "promoting/disturbing impacts" leads to an insufficient modeling, in particular with regard to sustainability aspects.

Thus, referring to some common "management rules" for sustainable development [16] the following fundamental questions remain open when work systems are reduced to a linear input-throughput-outputprocess:

1) Where does the input (above all energy and matter) originally come from and what are the (pre-) conditions for its genesis?

2) How has its use to be managed to keep regeneration ongoing (renewable resources) respectively to replace its function on the long term (nonrenewable resources)?

3) Where does the output (energy', matter') go to and which impact does it have on the surrounding systems?

4) What needs to be done to prevent damages through harmful outputs (e.g. toxic waste, but also harmful products per se) and to sustain the functions of receptor areas? 
5) How does the work system itself influences "external" promoting/disturbing impacts?

6) How can the interaction between social and technical parts of the system be optimized?

7) Which human and social capital as well as specific needs do the working individuals bring along (also beyond their recent tasks)? How do we manage and develop these in the best way?

\subsection{Socio-technical systems approach}

Starting point for the socio-technical systems approach was the famous coal mining study by Trist and Bamforth at the end of the 1940s [17]. After the implementation of a new (and technically more sophisticated) method of coal mining, the performance of the mining teams did not increase as expected, but suffered from the concomitant changes in social and organizational team structure.

By recognizing the interaction between people and technology in workplaces, the socio-technical systems approach consequently postulated the necessity for a "joint optimization" of both, social and technical sub-systems [18]. These findings emphasize the phenomena of emergence and coherence: Combining "optimized" sub-systems does not necessarily lead to an overall systems optimum - proofing again that the whole is greater than the sum of its parts.

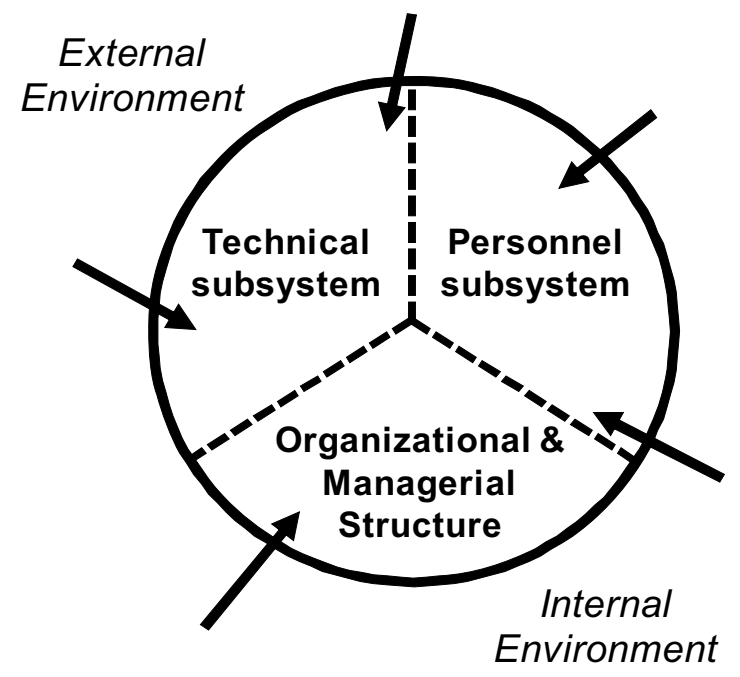

Figure 2: Basic macroergonomic work systems model [cp. 18]

Socio-technical systems theory is also the basis for macro-ergonomics [18]. In this context Hendrick defines a work system as consisting "of two or more persons interacting with some form of (1) job design,
(2) hardware and/or software, (3) internal environment, (4) external environment, and (5) an organizational design (i.e. the work system's structure and processes)." [19, p. 1]

Referring to the above formulated questions (Paragraph 4.1), the socio-technical systems approach mainly addresses questions 5-7 and delivers important milestones on the way to a comprehensive modeling of work systems. While the linear work system model considers social and organizational impacts rather as independent "environmental" variables (cp. questions 5\&6), these aspects are explicitly part of a socio-technical systems design.

And also the relevance of human and social capital and the individual needs of the working person are emphasized (cp. question 7): In the coal mining example, safety needs of the miners and social capital in form of trust between team members played a major role for the performance of the work system. As these needs became unsatisfied and social capital was destroyed by implementing the new mining method performance decreased.

In general, one can state that socio-technical systems design per se opens the perspective of ergonomics/human factors research towards a systemic understanding of work systems as being embedded in super- and subordinated systems: "Technology and human interact and they do so within a larger organizational context. Organizations operate within larger environmental systems and therefore it behooves the ergonomist to know enough about the larger system factors" [18, p. 83].

With socio-technological systems design, Zink proposes a further enhancement of modeling work systems [20]. As economic and ecological considerations are explicitly included here, this development strongly matches with sustainability requirements.

\subsection{Sustainable Work Systems}

As mentioned above, the socio-technical systems approach (respectively macro-ergonomics systems design) leads to a much more comprehensive and systemic modeling of work systems than the "common" linear understanding. It also integrates aspects of internal and external environment in the form of stakeholder requirements as well as other aspects influencing the behavior and performance of 
the work system [18]. This is - assuming a quite broad definition of the term "stakeholder" also highly appropriate for a sustainability perspective on work systems.

But this understanding of a work system's environment does not necessarily comprise the aspects formulated in the questions $1-4$, which deal with preserving capital stocks as well as the regeneration and sustainable use of resources. For these aspects, we need to further enlarge the perspective of work system modeling. A first proposal for such a general sustainable work system model is shown in Figure 3.

It tries to illustrate the definition elements of sustainable work systems as they are e.g. formulated by Docherty et al. [3 p. $3 \mathrm{ff}$.$] :$

- "A sustainable work system is able to function in its environment and achieve economic or operational goals.

- This functioning also entails development in various human and social resources engaged in its operations.

- Employees' capacity to deal with the world's demands grows through work-based learning, development, and well-being.

- The growth of social resources is secured through equal and open interaction among various stakeholders, leading to better mutual understanding and a greater capacity for collaboration.

- The diversity and regeneration potential of ecological resources are safeguarded as well."

Additionally, the following definition by Eijnatten [9, p. 53] emphasizes different "sustainability purposes" on individual, organizational and societal level:

"A Sustainable Work System is a work system in which the quality of work (i.e. employee's health, well-being, and personal development); the quality of the organization (productivity, efficiency, the ability to meet the challenges of tomorrow's business); and the quality of connections with the environment (both nature and society) are constantly kept at the same high levels. Sustainable Work Systems should reproduce resources $[. .].[t]$ hey develop by growth in the amount of resources in a reproduction cycle."

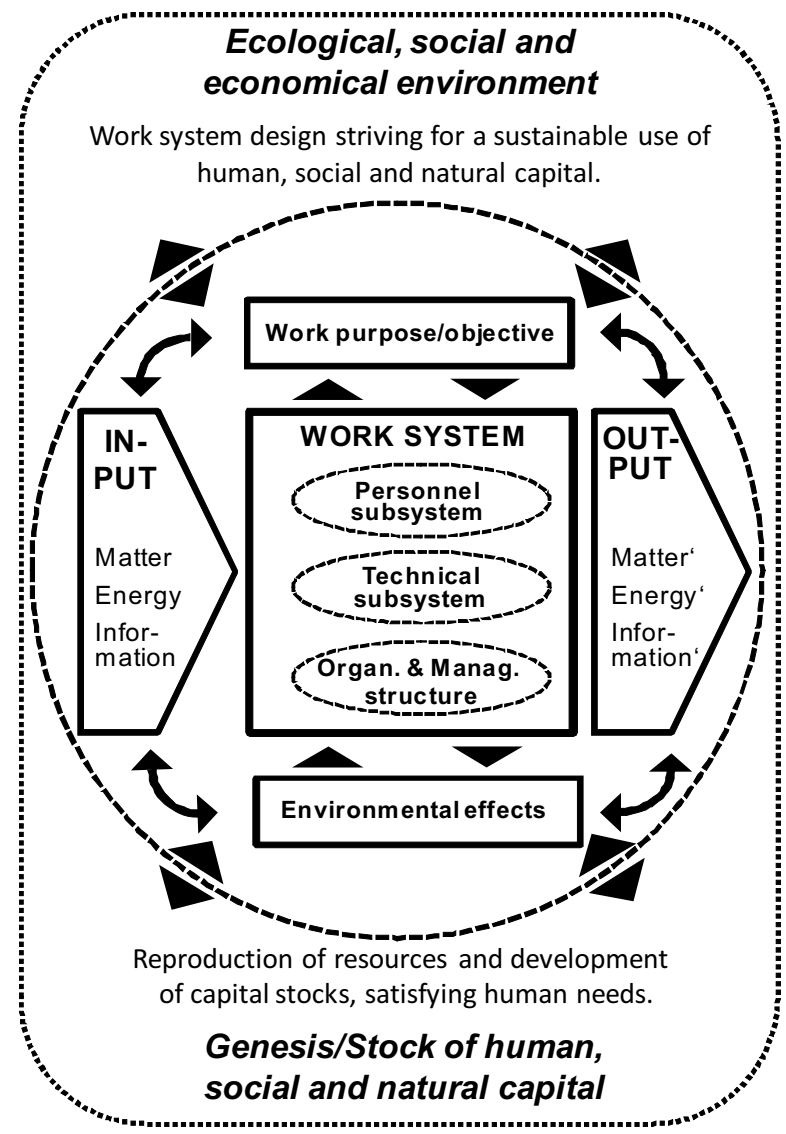

Figure 3: Proposal for a sustainable work system model (own figure)

But of course, these different purposes for sustainability are not independent from each other and can only be achieved permanently, when they meet overall sustainability targets of our global social system (as it was exemplified by the above mentioned autonomy principles of the viable systems theory in Chapter 3). Consequently work system sustainability (or organizational/corporate sustainability) can never be an end it itself and not be seen as an isolated target.

\section{Conclusion}

In praxis, striving for "real" sustainability often is a hard job as systemic thinking in long-term and complex interdependencies is just not in the human nature. Besides this, all organizations, work systems as well as individuals only have limited resources to cope with the "daily business" and to meet the needs of their relevant stakeholders. Consequently, arguing that a sustainable work system or organization should 
have all (potential) stakeholders and (possible) relations in mind seems indeed to be a legitimate claim, but does not lead to realizable outcomes in practice. Rather, dealing with resource scarcity and balancing conflicting demands are important individual as well as organizational capabilities on the way towards sustainable development. But of course, sustainability requirements claim for a more comprehensive thinking and modeling of reality, as this paper tried to show.

Thereby, sustainability principles are anchored in the basic understanding of human factors and ergonomics since its origin in the 19th century. The satisfaction of human needs and a balance between "what is good for ourself" and "the common welfare" (as mentioned in the early definition of Jastrzebowski in 1857 [21]), or - in other words - between "human well being" and "overall system performance" (IEA 2000 [5]) as well as an overall stakeholder orientation coupled with a triple-bottom line approach (GfA 1999 [22]) delineate the former and "modern" selfconception of our discipline. Of course, really sustainable paths do not exist on paper, but deploying the paradigm of sustainable development to an operational level is not an exclusive problem of human factors/ergonomics.

The proposed work system model which was developed in this paper bases on existent work system concepts augmented with general principles of systemic modeling relevant for focusing on sustainable development. It aims to visualize the requirements coming along with a sustainable work systems design and to deliver some kind of a conceptual framework for the link between human factors/ergonomics and sustainability research.

\section{References}

[1] WCED, Our common future, Oxford University Press, Oxford, 1987.

[2] P. Docherty, M. Kira, A.B. Shani (eds.), Creating sustainable work systems. Developing social sustainability, 2. ed., Routledge, London, 2009.

[3] P. Docherty, M. Kira, A.B. Shani, What the world needs now is sustainable work systems, in: P. Docherty, M. Kira, A.B. Shani (eds.), Creating sustainable work systems. Developing social sustainability, Routledge, London, 2009, 1-21.
[4] I. Ehnert, Sustainable Human Resource Management: A conceptual and exploratory analysis from a paradox perspective, Physica, Heidelberg, 2009.

[5] IEA (International Ergonomics Association), Ergonomics International News and Information - August 2000, Marshall Associates, London, 2000.

[6] S. Beer, Decision and Control, London et al., 1966

[7] W. R. Ashby, An Introduction to Cybernetics, London, 1970.

[8] H. Ulrich, Management, Bern, 1984.

[9] F.M. v. Eijnatten, From Intensive to Sustainable Work Systems: The Quest for a New Paradigm of Work, TUTB-SALTSA Conference, Brussels, 25-27 September 2000, 47-66

[10] D.H Meadows, D.L. Meadows, J. Randers, Beyond the limits. Global collapse or a sustainable future, Earthscan Publications, London, 1992.

[11] S. Beer, Brain of the firm, Chichester et al., 1984.

[12] F. Malik, Strategie des Managements komplexer Systeme: ein Beitrag zur Management-Kybernetik evolutionärer Systeme [Strategy of the Managemet of Complex Systems], Bern et al., 1996.

[13] S. Alter, Service system fundamentals: Work system, value chain, and life cycle, in: IBM Systems Journal, 47 (1), 71-85, 2009

[14] C.M. Schlick; R. Bruder, H. Luczak (2010): Arbeitswissenschaft [Ergonomics], Springer, Heidelberg et al, 2010.

[15] Verband für Arbeitsstudien und Betriebsorganisation (REFA Group), Lexikon der Betriebsorganisation [Encyclopedia of Company Organization], Hanser, München, 1999.

[16] The Federal Government, For a SustainableGermany: Progress Report 2008 on the National Strategy for Sustainable Development, Press and Information Office of the Federal Government, Berlin, 2008.

[17] E.L. Trist, K.W. Bamforth, Some social and psychological consequences of the long wall method of coal getting, in: Human Relations, 4, 1951, 3-38.

[18] B.M. Kleiner, Macroergonomics: Analysis and design of work systems, in: Applied Ergonomics, 37, 2006, 81-89.

[19] H.W. Hendrick, H.W., B.M. Kleiner, Macroergonomics: Theory, Methods, and Application, Lawrence Erlbaum, Mahwah, N.J./London 2002.

[20] K.J. Zink, Safety and quality issues as part of a holistic (i.e. socio-technological) approach, in: International Journal of Occupational Health and Safety and Ergonomics, 5, 1999, 279-290.

[21] W. Jastrzebowski, An Outline of Ergonomics or the Science of Work based on the Truths drawn from the Science of Nature, in: Przyroda I Przwmsyl [Nature and Industry], 29, 1857 (reprinted by the Central Institute for Labour Protection, Warsaw, Poland 2000).

[22] GfA (Gesellschaft für Arbeitswissenschaft), Selbstverständnis der Gesellschaft für Arbeitswissenschaft e.V. [Mission of the German Ergonomics and Human Factors Society], GfA-Press, Dortmund, 1999. 